\title{
Remix, mashup, paródia e companhia: por uma taxonomia multidimensional da transtextualidade na cultura digital
}

Remix, Mashup, Parody and Beyond: Towards a Multidimensional Taxonomy of Transtextuality in Digital Culture

Marcelo El Khouri Buzato*

Universidade Estadual de Campinas

Campinas - São Pauo / Brasil

Dáfnie Paulino da Silva**

Universidade Estadual de Campinas

Campinas - São Pauo / Brasil

Débora Secolim Coser***

Universidade Estadual de Campinas

Campinas - São Pauo / Brasil

Nayara Natalia de Barros****

Universidade Estadual de Campinas

Campinas - São Pauo / Brasil

Rafael Salmazi Sachs*****

Universidade Estadual de Campinas

Campinas - São Pauo / Brasil

RESUMO: Remix e mashup designam formas textuais, técnicas de produção e métodos criativos que se desenvolveram em conjunto com as técnicas analógicas de reprodução de obras musicais e cinematográficas no século XX. No âmbito da cultura digital, em face da automação de processos de edição e montagem, e da

\footnotetext{
* mbuzato@iel.unicamp.br

**1afehospel@gmail.com

*** deboracoser@gmail.com

**** nayara.natalia.barros@gmail.com

***** rafael.sachs@gmail.com
} 
maior agilidade na recuperação e circulação de acervos midiáticos em escala global, remix e mashup difundiram-se como elementos centrais de práticas discursivas que vão desde o puro entretenimento até a participação cívica, passando por diversas formas de produção de conhecimento. O presente trabalho busca contribuir para uma inserção mais significativa de remix e mashup no rol dos objetos de estudo em Linguística Aplicada de duas formas. Inicialmente, apresenta um estado da arte em que mostra as diversas concepçōes e ramificações de remix e mashup já estabelecidas na literatura, ressaltando as diferenças mais relevantes entre ambos. Em seguida, apresenta uma proposta taxonômica que abrange remix e mashup enquanto produtos textuais, técnicas de produção e métodos de criação, e situa os seus diferentes tipos no quadro geral das relações transtextuais como as que os linguistas aplicados já estão acostumados a lidar. Em conclusão, relembra-se que a presente proposta não faz mais do que estender para o âmbito da cultura digital uma longa tradição de estudos sobre a força do hibridismo nas dinâmicas culturais e seu potencial para a formação de cidadãos críticos capazes de protagonizar transformaçōes sociais.

PALAVRAS-CHAVE: remix; mashup; cultura digital; transtextualidade; hibridismo.

ABSTRACT: Remix and mashup designate textual forms, production techniques and creative methods that were developed in conjunction with the analogical reproduction techniques for music and film in the Twentieth Century. In the context of digital culture, in the face of automated editing and montage, and of greater flexibility in the recovery and circulation of media collections on a global scale, remix and mashup have spread as central elements of discursive practices that range from sheer entertainment to civic participation, to various forms of knowledge production. This study aims to contribute to a more meaningful integration of remix and mashup in the list of the objects of study in Applied Linguistics in two ways. Initially, we present a state of the art displaying the various concepts and ramifications of remix and mashup already established in the literature, highlighting the most significant differences between them. Then we put forward a taxonomy covering remix and mashup as textual products, production techniques and methods of creation, and we situate them in the overall ecology of transtextual relations applied linguists are already used to handling. In conclusion, it is recalled that this proposal does nothing but extend to the scope of digital culture a long tradition of studies on the strength of hybridity in cultural dynamics, and its potential for the formation of critical citizens capable of leading social change.

KEYWORDS: remix; mashup; digital culture; transtextuality; hybridity. 


\section{Introdução}

Concebemos cultura digital como um conjunto de processos e produtos de significações partilhados por pessoas que não apenas utilizam as tecnologias digitais da informação e comunicação de forma integrada ao seu cotidiano, como as usam para apoiar e expandir uma certa mentalidade (LANKSHEAR; KNOBEL, 2007) vinculada às sociedades pós-industriais, a qual privilegia a participação coletiva e o trabalho distribuído em rede em práticas cívicas, de consumo, de lazer, de aprendizagem (COSER, em preparação), de produção e gestão do conhecimento, de identificação (LEMKE, 2009) e de construção subjetiva (BUZATO, 2012). Situamo-la, ademais, num processo histórico mais geral, pelo qual as delimitaçóes entre as posiçōes de produtor e de consumidor no campo da produção midiática tornam-se muito mais porosas (JENKINS, 2009 [2006]; BRUNS, 2007; DEUZE; BRUNS; NEUBERGER, 2007). Embora a abolição total dessa hierarquia de posições seja claramente utópica (SONVILLA-WEISS, 2010), é cada vez mais evidente que a hegemonia da indústria cultural sobre a guarda, circulação e expansão dos conteúdos midiáticos se enfraquece, cedendo espaço, por exemplo, para práticas de curadoria digital (BARROS, em preparação) e de produção de conteúdos protagonizada por fã̃s (SACHS, 2012; SILVA, 2012).

No presente trabalho destacamos, no contexto desse universo de práticas, dois tipos de produtos e/ou processos técnico-semióticos que vêm se tornando emblemas da cultura digital, embora seus princípios constitutivos e funcionais, assim como suas formas iniciais de mediação tecnológica, lhe sejam anteriores: remix e mashup.

Nossa proposta básica de trabalho é situar tais objetos na "ecologia textual" com que nos habituamos a trabalhar em Linguística Aplicada, de modo a contribuir para uma melhor inteligibilidade dos modos e efeitos do uso da linguagem na cultura digital de modo geral.

Partimos da constatação de que a pesquisa sobre a produção textual/ discursiva da cultura digital no âmbito da Linguística Aplicada brasileira tem sido pautada, grosso modo, por uma variedade de perspectivas teóricas consideradas tradicionais em Linguística (marcadamente, da Linguística Textual, da Sociolinguística Interacional, da Análise do Discurso etc.) em diálogo com teorias ditas "do digital", usualmente formuladas no âmbito dos estudos de Comunicação e Mídias (BOLTER; GRUSIN, 2000; MANOVICH, 2001), das Ciências da Computação (NIELSEN, 2006; CONKLIN, 1987), e ainda com leituras do digital feitas por outras disciplinas como a Semiótica 
(LEMKE, 2010), a Teoria Literária (NELSON, 1992; LANDOW, 1992), e a História (CHARTIER, 2002), entre outras.

Entendemos que esse caminho, que se tem mostrado produtivo para a disciplina, ainda não está suficientemente firmado nos casos do remix e do mashup, ao menos até onde nos foi possível investigar, e que, independentemente da utilidade de conceitos como hipermodalidade gênero digital, entre outros, para o aumento da inteligibilidade sobre o assunto, há toda uma multiplicidade e especificidade de processos e efeitos de sentido vinculados a remix e mashup que esses conceitos não esgotam.

Visando a contribuir para a diminuição dessa lacuna, portanto, definimos três objetivos específicos para este trabalho: primeiro, reunir, dentre as informações básicas sobre remix e mashup disponíveis na literatura, aquelas que julgamos relevantes para a descrição desses objetos na Linguística Aplicada; segundo, elaborar uma proposta de classificação/taxonomização multidimensional desses objetos que possa, eventualmente, ser útil para o linguista aplicado que pretenda investigar correlações entre tipos específicos de remixes e mashups e práticas sociais (letramentos) específicos; e, finalmente, situar os tipos de remixes e mashups constantes de nossa proposta no quadro mais amplo das relações e produções transtextuais já tradicionalmente estabelecido na Linguística Aplicada a partir da Teoria Literária e da Linguística Textual.

Ao longo desse percurso, ilustraremos nossas propostas com exemplos disponíveis na Web à época da preparação deste trabalho, alguns dos quais eram, então, partes integrantes das pesquisas em andamento no Grupo de pesquisa Linguagem, Tecnologias e Pós-sociedade/humanidade (LiTPos), sediado no Instituto de Estudos da Linguagem da Unicamp. Não temos aqui qualquer ambição totalizadora: queremos apenas propor uns poucos "tipos ideais" weberianos que possam ser úteis, conscientes que somos do esforço reducionista que obrigatoriamente acompanha todo empreendimento classificatório. Entendemos, contudo, que, por ser multidimensional, nossa proposta tenta, ao menos, reduzir a complexidade dos objetos sem apagar-lhes a constituição eminentemente híbrida que os torna singulares e dignos de nota.

Ressaltamos ainda que remix e mashup são identidades relacionais e contingentes, isto é, o que é remix ou mashup sempre o é para alguém específico, em alguma situação específica. Isso porque, é claro, a capacidade de um intérprete/interlocutor reconhecer um texto/interlocutor como um híbrido é dada pelo repertório de referências que permitem a identificação de traços remissíveis a outros objetos ou fontes. Dito de outra forma: o leitor de 
um remix ou mashup que os reconhece como tal é necessariamente um transleitor e, assim como seu produtor (urdidor ou montador), é sempre um transletrado (THOMAS, 2007). É nesse sentido que remix e mashup precisam ser pensados não apenas multidimensionalmente, mas também por meio da noção de gradiente, isto é, em termos de diferentes graus de efetivação dos múltiplos potenciais de sentido nele programados pela justaposição de intertextos, discursos, modalidades semióticas e referências contextuais.

\section{Remix e mashup: um estado da arte}

Parte do que chamamos aqui de cultura digital manifesta-se de modo inequívoco no que Navas define como "cultura remix", isto é, "uma atividade global que consiste na troca criativa e eficiente de informações, possibilitada pelas tecnologias digitais e apoiada nas operaçōes de recortar/copiar e colar" (NAVAS, 2010, p. 159). ${ }^{1}$ Embora a prática e a técnica do remix remetam a diversas tradiçôes artísticas e midiáticas anteriores, como as de colagem e montagem nas artes plásticas e no cinema do início do século XX, Navas (2010) explica que o conceito, tal qual aplicado hoje, remonta a certas produçōes musicais típicas da cidade de Nova York nas décadas de 1960 e 1970, que consistiam em elaborar uma reinterpretação de uma música preexistente para retomar, de maneira indireta, "a aura espetacular" ${ }^{2}$ da versão original (NAVAS, 2010).

Ao longo do século XX, os remixes musicais foram se disseminando (LANKSHEAR; KNOBEL, 2008) e assumiram diversas formas, de modo que a prática passou a comportar, muitas vezes, a mistura de elementos de duas ou mais canções, como nos chamados megamixes, criados nos anos 1980 como extensão dos medleys musicais. ${ }^{3}$ Para Navas (2010), ambos os tipos de composição foram os precursores das primeiras obras musicais denominadas mashups.

\footnotetext{
${ }^{1}$ A tradução é nossa, aqui e em todas as demais citações deste trabalho que foram retiradas de originais em inglês.

2 Navas (2010) cunha o termo tendo como parâmetros o conceito de aura em Walter Benjamin (2000 [1955]) e o de "espetacular" em Guy Debord (2004 [1967]), pois considera que uma obra objeto de remix tem seu valor de reconhecimento cultural atrelado ao seu valor de exibição.

${ }^{3}$ No medley, uma u'nica banda tocava duas ou mais mu'sicas em seque^ncia, "com o objetivo de animar os ouvintes ou quem estava dançando" (NAVAS, 2010, p. 165); já no megamix, os DJs, com os mesmos objetivos, passaram a utilizar, em sequência, samples de diversas mu'sicas numa u'nica performance.
} 
Lankshear e Knobel (2008) apontam que, nos anos 1990, essas produçōes se popularizaram de maneira marcada em diversos gêneros musicais, sobretudo com o desenvolvimento de tecnologias e softwares de digitalização do som. Para Navas (2010), tal popularização foi ainda além: ao longo do século XX, o mashup teria se instituído como modelo conceitual para criações não apenas na música, mas em diversos tipos de mídia (arquitetura, fotografia, software etc.).

\subsection{Remix e mashup: entendendo as diferenças e suas consequências}

Segundo as definiç̧óes de Navas (2010), a característica fundamental de todo remix é sua filiação a uma obra original, à qual se reporta de alguma maneira, com graus variados de diferenciação. Os mashups, por sua vez, são remixes caracterizados pela combinação de elementos de duas ou mais fontes numa nova obra, produto ou serviço, que pode ou não retomar explicitamente essas fontes (NAVAS, 2010).

Analogamente, Sonvilla-Weiss (2010) define remixes e mashups como produtos de práticas de montagem, sampleagem (copiar e colar) e colagem que objetivam a criação de algo novo. Como Navas (2010), Sonvilla-Weiss também caracteriza mashups como remixes que combinam elementos de fontes variadas, unindo "diferentes informaçôes, mídias ou objetos sem mudar sua fonte original de informação", de modo que "o formato original permanece o mesmo e carrega os traços da forma e do conteúdo originais, embora recombinados em contextos e designs diferentes e novos" (SONVILLA-WEIS, 2010, p. 9).

Essas definiçōes não deixam de abarcar, de certo modo, outras que não diferenciam remix de mashup, como a de Lankshear e Knobel-e, de maneira similar, a de Lessig (2004) - que descrevem remix como "a prática de tomar artefatos culturais e combiná-los/manipulá-los de modo a gerar um novo tipo de mistura criativa" (LANKSHEAR; KNOBEL, 2008, p. 1). Contudo, Navas (2010) e Sonvilla-Weiss (2010) distinguem das demais misturas (mixes) de elementos aquelas que retomam de maneira mais evidente os textos fonte e se propõem, declaradamente, a combinálos e/ou integrá-los (mash them up); afastam-se, assim, de autores como Lamb (2007), que utiliza remix e mashup inadvertidamente como sinônimos.

O escopo de aplicação de cada conceito também varia entre os autores: se alguns se limitam a exemplos de músicas, outros, como Navas (2010, p. 168), descrevem como mashups o brinquedo de nome Spider-Hulk (que não é nem o Homem-Aranha, nem o Hulk, mas tem traços de ambos), os gigantescos painéis publicitários aplicados sobre fachadas de edifícios em 
grandes cidades (nesse caso, um mashup, para ele, de propaganda com arquitetura) e a própria interface dos sistemas operacionais de computadores utilizada até hoje (em que as informaçôes e comandos de uso do computador compóem um mashup com a interface do desktop ou área de trabalho). Consideramos que tal abertura ilimitada contribui para o enfraquecimento dos conceitos de remix/mashup e remete a outros, mais abrangentes e mais bem firmados na literatura, já em uso no campo dos estudos sobre novos letramentos, como o de hibridismo (BUZATO, 2007; 2012). Vamos nos limitar, portanto, a pensar remixes e mashups como textos e operações centrais aos novos letramentos no âmbito da cultura digital.

Para nós, as diferenças de concepção mencionadas não são necessariamente fontes de contradição a se eliminar. Com efeito, mais importante que discutir definições terminológicas e delimitações conceituais é compreender que as práticas de remixagem são motores fundamentais do funcionamento da própria cultura disponíveis desde sempre e que, neste momento, em função da nova base tecnológica, tornaram-se mais evidentes e mais prolíficos. Assim, retomamos aqui a percepção generalizada no campo aplicado dos estudos da linguagem de que a existência empírica do hipertexto eletrônico apenas tornou tangível uma concepção de textualidade e significação que o pós-estruturalismo já propusera em termos teóricos, e projetamos tal percepção sobre remix e mashup enquanto formas empíricas que tornam tangíveis, a todo momento, nos circuitos de produção e circulação midiática, a heterogeneidade e o hibridismo constitutivos de que nos falam há décadas os teóricos da cultura e os estudos culturais (FRIEDMAN, 2002; HALL, 2003).

\section{Uma proposta taxonômica multidimensional}

Se remix e mashup são justamente objetos da cultura digital que personificam o hibridismo e a heterogeneidade constitutiva, por que então propor uma taxonomia? Primeiramente, porque entendemos que os processos e produtos que chamamos de remix e mashup têm propriedades em comum que propiciam seu agrupamento em conjuntos funcionais. Segundo, porque defendemos que o caráter multidimensional da taxonomia que estamos propondo faz uma grande diferença, pois permite a um mesmo elemento classificado pertencer a tantos paradigmas quantos forem as suas possibilidades de compartilhamento de traços com outros elementos. Finalmente, porque é nossa convicção que uma tentativa de classificação ressaltará, em lugar de silenciar, a complexidade desses objetos e seu consequente potencial para a 
renovação dos esquemas classificatórios com os quais nossa comunidade científica vem trabalhando.

Ao mencionar uma classificação multidimensional, referimo-nos à classificação de remix e mashup enquanto (i) procedimentos operacionais (ou técnicas), (ii) processos (ou métodos) criativos e (iii) produtos discursivos (objetos semióticos funcionais dentro de uma cultura ou sistema sociotécnico). Cada uma dessas dimensões está, obviamente, ligada às demais de maneira intrínseca, mas, ao mesmo tempo, oferece tipos diferentes de sistematicidade que vale a pena especificar e contrastar.

\subsection{Remix e mashup como procedimentos operacionais (técnicas)}

Enquanto procedimentos operacionais, remix e mashup são aparentados da colagem e da montagem, técnicas extremamente férteis de criação de novos objetos a partir de outros já existentes, as quais foram exaustivamente pesquisadas pelas vanguardas europeias no início do século XXe, mais adiante, levadas ao cinema, à fotografia e a outras mídias. A ação básica envolvida é o copiar e colar ou, no jargão dos músicos, samplear, isto é, digitalizar uma amostra de um objeto-fonte, a qual pode vir a tornar-se um padrão ou motivo a ser colado diversas vezes em fases posteriores de processos específicos de composição vertical ou horizontal (ver subseção 3.2).

A infraestrutura técnica da cultura digital facilitou enormemente aos produtores de remixes e mashups a obtenção de fontes para sampleagem, bem como a realização de montagens on the fly (em tempo real, por meio de tentativas e experimentações sucessivas), visto que cada sample é apenas uma instanciação de um arquivo digital que pode ser multiplicado ad infinitum e manipulado automaticamente. Essas novas possibilidades técnicas - new technicalstuff, no vocabulário de Lankshear e Knobel (2007) - têm repercussões quantitativas e qualitativas importantes. Do ponto de vista quantitativo, a automatização das operações de sampleagem e (re)mixagem permitiu uma avalanche de novas produçóes midiáticas disponibilizadas on-line tanto por profissionais quanto por amadores/curiosos e pelos produsuários (produsers) de que falam Bruns (2008) e Jenkins (2009 [2006]). Essas novas produções, por sua vez, ficam disponíveis para novas apropriaçōes e recombinações que, mais tarde, voltam para a rede (ou invadem a programação da TV ou do rádio), muitas vezes na forma de réplica direta ao remix/mashup "original", estendendo cadeias dialógicas e intertextuais. Além disso, nota-se aqui a incidência do que Manovich (2003, p. 18) chamou de "dialética da transformação de quantidade em qualidade", em que uma 
multiplicação muito intensa da quantidade de operações e tentativas possíveis com um mínimo de tempo despendido leva, eventualmente, a resultados qualitativamente diferenciados.

Obviamente, observa-se também uma banalização da sampleagem enquanto operação aplicada a práticas que, por justiça, não se deveriam considerar como de remix ou de mashup, em especial as práticas de reblogagem ou retuitagem que constituem o grosso da atividade em certas plataformas da Web 2.0 (SACHS, 2012), as pesquisas escolares "copiadas de Internet" e coladas num papel a ser entregue ao professor, as correntes de e-maile tipos variados de $S P A M$, a circulação de memes de Internet sem valor artístico ou político relevante, entre outras. É justamente por conta dessa banalização que julgamos pertinente estabelecer uma diferença entre remix/mashup enquanto meras operações e remix/mashup enquanto processos ou métodos criativos que são motores da cultura digital.

\subsection{Remix e mashup enquanto processos/métodos criativos}

Enquanto processos/métodos, remix e mashup correspondem a usos especializados de dois modos básicos de montagem: sequenciação ou intercalação (montagem horizontal) e sobreposição ou composição (montagem vertical).

A sequenciação (intercalação) corresponde à justaposição ou encadeamento de segmentos sampleados, respeitando-se ou não a ordem em que apareciam nas obras-fonte. $\mathrm{O}$ exemplo óbvio aqui é a montagem cinematográfica simples, em que um montador, orientado pelo diretor, recorta e cola segmentos de diferentes rolos (ou arquivos de vídeo digital) contendo cenas e sequências distintas para construir uma narrativa com intercalações, flashbacks, flash-forwards etc. Já a sobreposição (composição) corresponde à agregação de diferentes camadas ou faixas simultâneas que passam a constituir uma unidade síncrona e sinóptica. $\mathrm{O}$ exemplo mais corriqueiro aqui seria o de uma peça audiovisual em que se agregam, em camadas, cinegrafia, música, tipografia, efeitos de finalização, animaçóes, fala, efeitos de transição etc.

O mais frequente é que os dois métodos apareçam juntos, como num filme (sequenciação) em que se "empilham" (sobreposição) camadas de cenas filmadas (live plates), animações e trilha sonora num mesmo conjunto de fotogramas. Existem, porém, algumas diferenças significativas entre os dois processos/métodos quanto à significação e aos letramentos envolvidos. Primeiramente, a montagem horizontal demanda que o produtor encontre pontos de conexão ("ganchos") entre fragmentos sampleados, isto é, elementos 
que estabeleçam continuidade, quer a partir de uma lógica temporal linear, como é mais comum, quer a partir de qualquer outra lógica que o leitor possa acompanhar. Tais "ganchos" podem ser formais - por exemplo, quando se juntam segmentos plasticamente (uma mesma paleta de cores ou uma mesma batida rítmica) ou conceitualmente contíguos (o todo e suas partes, causa e consequência, imagens constitutivas de uma metáfora ou comparação etc.) ou podem também ser mais evidentes em termos de conteúdo - por exemplo, quando diferentes fragmentos de uma ou várias açóes são sequenciados num mesmo cenário, ou ainda quando as etapas postas em sequência tratam de um mesmo objeto concreto (por exemplo, nas exibiçōes, em tela, de fotos de noivos ou de um aniversariante numa "retrospectiva" audiovisual).

Já a montagem vertical demanda "pontos de assentamento", isto é, elementos que permitam às diferentes camadas sobrepostas assentarem-se umas sobre as outras sem "deslizar", preservando, assim, o efeito de sentido dado pela sua atuação conjunta simultânea. Esses pontos podem ser elementos formais, como quando um DJ sobrepõe uma canção antiga a uma batida mais contemporânea, tomando como elemento de assentamento o divisor comum entre dois ou mais ritmos e andamentos. Ou, para dar um exemplo visual, considerem-se boletins meteorológicos de telejornais nos quais formas geométricas, alturas e profundidades dos praticáveis utilizados no cenário são "encaixados" precisamente nas formas dos elementos gráficos sobrepostos no vídeo (mapas e gráficos, por exemplo) e ainda usados como referência física e/ou mental para o apresentador encaixar seus gestos e movimentos corporais na cena.

No caso das produções ditas "originais" ou não derivadas, nas quais se espera que o objeto resultante aparente ser "sem costuras", não basta localizar os ganchos e pontos de encaixe: é necessário sustentar a continuidade formal e semântica entre os elementos combinados. Em alguns casos, é necessário que se façam pequenos ajustes que visem "disfarçar" a montagem. Por exemplo, numa sobreposição com uso de chroma key entre um ator que faz o papel de um astronauta e uma foto digital de uma cratera lunar que serve de fundo, é de se esperar que o ator vista um traje espacial e que, ao andar, simule os "pulinhos" dados por astronautas reais naquele cenário real. Se, na cena seguinte, aparece um alienígena feito em animação gráfica, os valores tonais, de foco, de luminosidade, de saturação, entre outros, devem ser calculados para se ajustar o mais proximamente possível daqueles do astronauta.

O que distingue mashups e remixes dessas montagens "usuais" é que, embora se vise um produto textual que se apresenta coerente e coeso semântica e morfologicamente, não é necessário - nem desejável, muitas vezes, no caso 
do mashup - que essa continuidade se apresente "sem costura". Isto porque, como já frisado, boa parte da força do texto derivado vem, justamente, da recuperação, na memória discursiva do leitor, das fontes combinadas.

Finalmente, é preciso ressaltar a complexidade semiótica inerente a esses métodos criativos, sobretudo quando envolvem a sobreposição e intercalação de diferentes modalidades e linguagens midiáticas, gerando, conforme Lemke (2002), uma multiplicação expressiva dos potenciais de significado oferecidos pelo texto.

No caso dos processos a que aludimos aqui, chama atenção a maneira como esse potencial multiplicativo é aproveitado não só para a produção de sentidos mais precisos e/ou menos domesticáveis por convençôes atinentes a este ou aquele sistema semiótico isoladamente (LEMKE, 2002), como também para contornar a falta de ganchos e encaixes "naturais" numa mesma modalidade entre duas ou mais fontes. Note-se, por exemplo, no mashup "O bonde das maravilhas (versão Teletubbie)", postado no YouTube, como, ao ajustar a velocidade do movimento corporal das personagens ao tempo exato da música, o produtor "gerou" o encaixe entre as coreografias do funk e do tema musical do programa, que serviram de fontes, produzindo o efeito de "teletubbies dançando funk", que dá comicidade ao texto.

A FIG. 1 sintetiza o que acabamos de expor acerca de remix e mashup enquanto processos criativos.

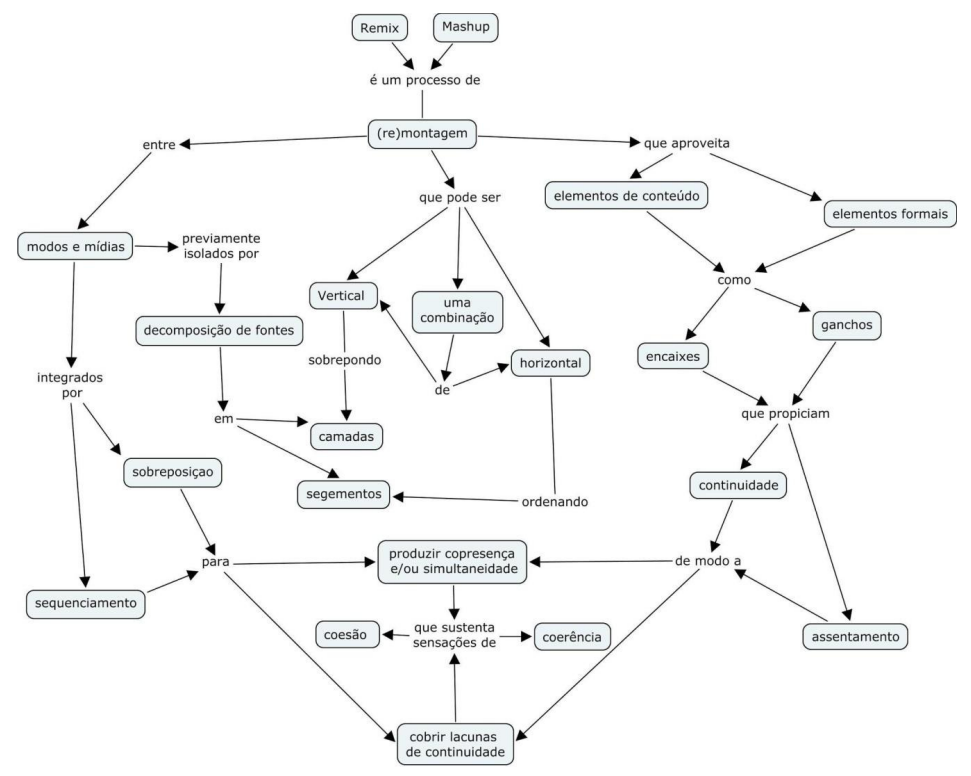

FIGURA 1 - Mapa conceitual síntese de remix e mashup enquanto processos criativos Fonte: Elaboração própria. 


\subsection{Remix e mashup enquanto artefatos técnico-semióticos (produtos)}

Mashups e remixes são também os nomes dados a diversos produtos concretos resultantes das técnicas e operações mencionadas na subseção anterior que, usualmente, circulam em formato digital por diferentes comunidades/ audiências, que podem considerá-los tanto "obras derivadas" como textos efetivamente "autorais". Acreditamos que é sobretudo essa dimensão "concreta" de remix e mashup que abordam as taxonomias já disponíveis na literatura, com destaque para a de Navas (2010), aparentemente a primeira e mais popular.

Para Navas, os remixes podem ser estendidos, seletivos ou reflexivos, e os mashups podem ser de serviços e de conteúdo, sendo estes classificáveis como regressivos ou reflexivos, e aqueles como integrativos ou agregativos (CHATTI et al., 2011), conforme esquematizado nas FIG. 2 e 3.

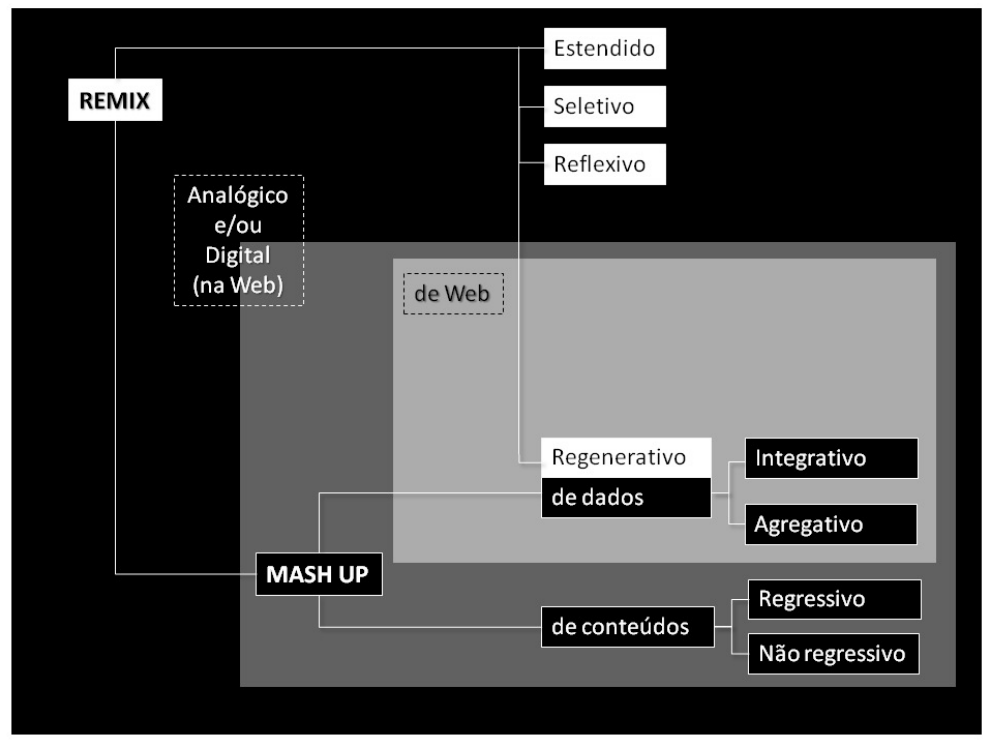

FIGURA 2 - Tipos de remixes enquanto produtos

Fonte: Elaboração própria.

Remixes estendidos são, fundamentalmente, versões prolongadas da obra-fonte que têm por objetivo aumentar o tempo de sua apreciação pelo público de um evento. É o caso, entre outros, das "versóes de festa" ou "versões de pista" de hits do momento. Um exemplo específico seria "Set Fire to the Rain (DJ Tyler Davey Extended Remix)", remix estendido do hit da cantora 
britânica Adele, que Davey assentou sobre uma base dançante e remontou com repetiçôes de alguns dos trechos intercalados por momentos de silêncio vocal e, consequentemente, de destaque para a melodia e para a base rítmica.

Os remixes seletivos, por sua vez, envolvem a adição e subtração de partes da peça-fonte sem que ela seja, contudo, excessivamente descaracterizada. No caso da subtração, são bons exemplos os chamados "filmes de 5 segundos" disponíveis no YouTube. Nessas peças humorísticas, um ou mais recortes mínimos da fonte (totalizando, idealmente, cinco segundos) são escolhidos para sumarizar a história de forma radical. Tome-se como exemplo o vídeo "Titanic in 5 seconds", constituído basicamente por uma montagem horizontal de três fragmentos: partindo de um fragmento da abertura do filme oficial, acompanhado pela música tema e título, passamos, abruptamente, para o momento em que o personagem J. B. Ismay diz "But this ship cannot sink!" (“Mas é impossível esse navio afundar!"); e, em seguida, para os últimos quadros da cena em que o navio é tragado pelo mar, ao som da música tema do filme, à qual se adiciona um efeito sonoro que indica um objeto sendo jogado na água.

Por fim, os remixes reflexivos, são (re)montagens que levam a sampleagem além do convencional, a ponto de produzir uma peça derivada que adquire uma "aura independente" (BENJAMIN, 2000 [1955]), ainda que partes da obra-fonte, ou mesmo seu nome, sejam propositalmente mantidas. Um caso representativo é "Gold Digger", um remix de Kayne West para o clássico de Ray Charles, "I've got a woman"; este, por sua vez, é também um remix reflexivo criado por Charles a partir da peça gospel intitulada It must be Jesus (FERGUSON, 2010; 2011;2012).

Convém destacar, acerca dos remixes reflexivos, que eles não se confundem com remakes ou versões autorais, pois, enquanto estas duas formas reforçam a aura do texto fonte, aplicando-lhe uma roupagem diferente, o remix reflexivo subverte o texto- fonte ao mesmo tempo em que explicita as referências a ele, ressaltando, consequentemente, os ganhos instaurados pela remixagem. Não é como revestir o texto fonte, mas como desnudá-lo para utilizar sua "roupa original" sobre um outro "corpo"!

No caso de "Gold Digger", enquanto o ritmo e a melodia marcam a referência à canção-fonte pelo canal sonoro, visualmente a referência é estabelecida pela presença de Jamie Fox, atuando como cantor. Como é sabido, Fox foi o ganhador do Oscar de melhor ator em 2004 por sua interpretação de Ray Charles no filme Ray, dirigido por Taylor Hackford. Trajando um blazer com camisa clara sem gravata, compatível com a imagem pública de 
Charles à época de seu auge, e imitando a voz de Ray à perfeição, como fez no filme, Fox troca o verso "She gives me money" do texto fonte por "She takes my money", referência à figura de uma "gold digger", isto é, uma mulher interesseira que explora economicamente seus parceiros sexuais.

Navas (2010) destaca ainda um quarto tipo de remix, que chama de remix regenerativo, equivalente, para ele, ao mashup reflexivo que nós optamos por chamar de mashup de serviços (de dados, de software) (ver FIG. 2).

Todo remix regenerativo/mashup reflexivo é criado, em princípio, com uma finalidade prática, da qual retira seu valor para o usuário/leitor comum, pouco importando, portanto, quais seriam suas obras-fonte. É o caso, segundo Navas (2010), do serviço Google News que, embora seja um agregador de notícias vindas de diversos sites jornalísticos, é muitas vezes tomado como veículo jornalístico em si pelo leitor, recebendo, por isso mesmo, o benefício da credibilidade de que gozam os provedores "oficiais" de notícias, como jornais, revistas, redes de TV etc.

Os remixes regenerativos/mashups de serviços podem ser de dois tipos: integrativos ou agregativos (CHATTI et al., 2011). Os agregativos são simples justaposiçôes de conteúdos oriundos de fontes diferentes numa mesma interface, como o próprio Google News, ou os videoblogs que utilizam inserts do YouTube, fotos do Flickr, tagclouds, feeds, banners e outros elementos vindos diretamente de fontes externas. São mashups que não envolvem o compartilhamento de dados entre seus serviços componentes e, por isso mesmo, não requerem habilidades avançadas de programação de seus produtores. Para montá-los, basta copiar partes de códigos gerados automaticamente pelos serviços-fonte (por exemplo, pela função "incorporar" do YouTube) e colá-los nos locais adequados do código gerador da apresentação na interface (por exemplo, no espaço reservado para posts em um blog).

Já os mashups de serviços integrativos são construídos pela articulação de interfaces de programação de aplicações (APIs) de diferentes serviços e fontes de dados, requerendo conhecimento técnico não trivial da parte do seu construtor e tornando difícil, pelo mero acesso à sua aparência na interface de consulta, determinar quais são suas fontes e de que maneira foram combinadas (CHATTI et al., 2011). Yee (2008) cita como exemplo o serviço cuja interface de usuário é retratada na FIG. 3. Por meio dele, é possível localizar em um mapa gerado pelo Google Maps o local exato no qual foi tirada determinada foto postada por um usuário do Flickr. 


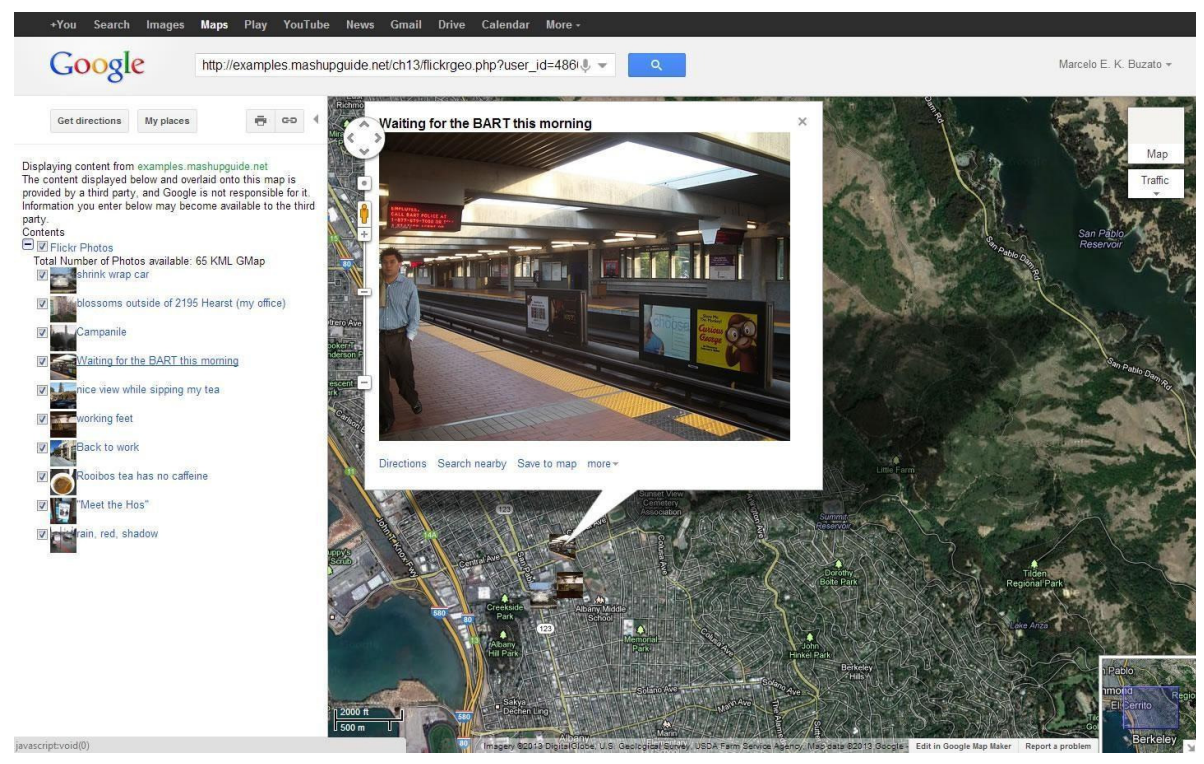

FIGURA 3 - Exemplo de mashup de serviço agregativo disponibilizado por Yee (2008)

Fonte: <http://goo.gl/maps/RlUH4>.

A integração se dá, neste caso, entre as APIs do Flickr, que fornecem as fotos públicas, e as do Google Maps, que fornecem o mapa e as capacidades de geoprocessamento, as quais "conversam" por meio de feeds 4 de KML, ${ }^{5}$ que transportam as coordenadas registradas pelo smartphone de quem postou a foto.

Finalmente, há o que chamamos de mashups de conteúdo (LAMB, 2007), que podem ser do tipo regressivo (NAVAS, 2010) ou não regressivo (nossa proposta de denominação). Os mashups de conteúdo do tipo regressivo são, para Navas (2010), aqueles que recuperam mais clara e explicitamente suas fontes, criando um efeito metassemiótico importante. Um exemplo é o vídeo "System of a Dilma", em que o DJ Faroff combinou partes do videoclipe da canção "Chop Suey!", da banda System of Down, com trechos de um discurso de Dilma Rouseff, então candidata à presidência do Brasil, de tal modo que Dilma parecesse interpretar a canção tal qual uma cantora de rock.

\footnotetext{
${ }^{4}$ Método de envio de dados em tempo real via Internet entre diferentes fontes e aplicativos on-line.

${ }^{5}$ Keyhole Markup Language. Trata-se de uma notação informacional para expressar anotações geográficas e de visualização em mapas baseados na Internet e/ou em programas de georreferenciamento, tais como o Google Earth.
} 
Com maestria, o produtor assentou sobre a linha melódica da peça punk frases proferidas por Dilma em seu comício que tinham estrutura métrica e rítmica congruente com a do texto fonte em inglês, aproveitando-se do fato de que Dilma aparece sobre um palco, de microfone em punho, como gancho para inseri-la imaginariamente no cenário de um show de rock. O DJ sampleou a palavra amor dita por Dilma e processou-a em um sintetizador para melodizá-la de forma congruente com a linha melódica do texto fonte. Para finalizar, encaixou a expressão "se Deus quiser", falada pela voz inconfundível do ex-presidente Lula, no lugar do verso "you wanted to" da letra original, ajustando sua velocidade/ritmo perfeitamente com a batida e a melodia daquela parte da canção.

O que vale ressaltar, neste caso típico de mashup de conteúdo regressivo, é a força do efeito metassemiótico obtido pelo produtor, o qual rivaliza, em importância, com a mensagem política pretendida. Tal rivalidade está claramente expressa nos comentários de usuários do YouTube destacados no quadro abaixo:

\section{QUADRO 1}

Postagens de usuários no YouTube acerca do mashup "System of a Dilma"

(1) "que@loku..kkkkkk"

(2) "sempre compartilhando pq esse é o melhor $\square$ vídeo .....não me canso de rever !!!!!!”

(3) "Genio.....Genio que fez esse $\square$ video..."

(4) “o vídeo ficou muito legal, mais @no PT só tem filho da puta! O pior partido que o país já teve que de esquerda não tem nada! Abaixo aos corruptos ! Guerra civil já!"

(5) “O VIDEO ÉTOP, pena q o governo $\square$ dela nao corresponde a exelencia do video [...] Fonte: <http://www.youtube.com/watch?v=AQPQKdg8UOg>.

Como se vê no QUADRO 1, o efeito metassemiótico é de tal magnitude que, ou se torna "a mensagem" do vídeo em si (comentários 1, 2 e 3), ou passa a integrar o conteúdo argumentativo em torno da sua mensagem-conteúdo, ocupando a posição de tópico/tema dos enunciados, como em 4 e 5.

Finalmente, propomos o termo "mashup (de conteúdo) não regressivo" para designar os casos em que (i) faltam ao leitor as referências necessárias para identificar as fontes como sendo distintas, ou (ii) as fontes são tantas, tão pouco notórias e tão bem "costuradas" (encaixadas e assentadas), que o mashup adquire o status de texto fonte perante o leitor, ou ainda (iii) as fontes são ostensivamente sugeridas ao leitor, ou claramente referenciadas, mas são fontes "sem aura" a ser reverberada, ou cujo encaixe e/ou assentamento não requer perícia, e vem a 
propósito de unificar determinada mensagem que carece de fundamentação. Ousando um pouco mais, do ponto de vista conceitual, podemos dizer que, em (i) e (ii), falamos sobre qualquer texto "comum", cuja heterogeneidade temática/ semiótica interna é desprezada/desprezível em seus usos cotidianos. Nisso residiria, ainda, uma certa semelhança entre textos do cotidiano (funcionais, formulaicos, cristalizados etc.) e mashups de serviços do tipo integrativo: assim como esses mashups, o texto dito "comum" é composto por enunciados cujo valor é constantemente regenerado pelas circulaçôes dialógicas de que participa, embora poucos leitores (usualmente apenas estudiosos da linguagem, artistas ou historiadores) se deem o trabalho de rastrear as "fontes" de tais circulaçóes e os modos de sua integração.

\section{Remix e mashup no quadro geral das manifestações da transtextualidade}

Tendo examinado remix e mashup enquanto processos criativos e apresentado um quadro taxonômico de remix e mashup enquanto produtos técnico-semióticos (textos), resta-nos tentar situar esses produtos/textos no quadro mais geral dos casos típicos de relações transtextuais já amplamente utilizado na Linguística Aplicada. Definir esse lugar nos parece necessário não apenas porque os estudos da linguagem se deparam cada vez mais com esses produtos nas situaçōes de uso da linguagem que buscam compreender, mas também para estabelecer uma salvaguarda contra a banalização desses conceitos que temos observado. ${ }^{6}$

Visando contribuir para este fim, buscamos subsídios em estudos tradicionais sobre transtextualidade e intertextualidade conhecidos no âmbito da Linguística Textual e da Teoria Literária. Propositalmente, deixamos de fora a maior parte dos estudos da Enunciação e Análise do Discurso, por entendermos que tais estudos são mais úteis para o estudo de remix e mashup

\footnotetext{
${ }^{6}$ Referimo-nos, aqui, por exemplo, ao importante documentário em quatro episódios Everything is a remix, produzido por Kirby Ferguson $(2010 ; 2011 ; 2012)$, um cineasta engajado na discussão sobre os limites do conceito de propriedade intelectual na cultura digital. Ferguson argumenta, de modo, a nosso ver, excessivamente vago e pouco fundamentado teoricamente, que tudo hoje é remix, desde cançôes plagiadas até automóveis de design "retrô". Apesar de reconhecermos a força de tais exemplos para a presente discussão, achamos que banalizar o conceito de remix dessa forma é contraprodutivo.
} 
enquanto enunciados situados do que enquanto processos criativos e produtos técnico-semióticos passíveis de taxonomização. Não desprezamos, obviamente, a necessidade do estudo dos tipos de remix e mashup em sua dimensão discursivo-enunciativa; apenas nos reservamos à opção de fazê-lo em outro trabalho, tendo conseguido consolidar o aqui presente. Da mesma forma, estamos cientes da utilidade de, futuramente, agregarem-se outros tipos subordinados de remix e mashup, assim como da necessidade de descreveremse com o mesmo nível de refinamento aqui proposto outros tipos de montagens digitais que não encontram lugar exato em nossa atual proposta, como, por exemplo, mosaicos e redublagens, entre outras. Acreditamos, contudo, que essas ressalvas não diminuem a utilidade da proposta em seu atual estágio de elaboração.

\subsection{A perspectiva da Linguística Textual}

Para Koch (2004), a intertextualidade é "um processo" em que "em um texto, está inserido outro texto (intertexto) anteriormente produzido, que faz parte da memória social de uma coletividade ou da memória discursiva [...] dos interlocutores" (KOCH, 2004, p. 146).

Koch (2004) explica que a intertextualidade manifesta-se tanto de forma explícita-quando o texto faz menção ao seu intertexto por meio de citações, referências, menções, resumos, resenhas e traduções, retomadas de turnos alheios com a devida sinalização num diálogo face a face, entre outros - como implícita - quando o intertexto é introduzido sem menção da fonte, para dar sequência à sua progressão argumentativa, para colocá-la em questão, para ridicularizá-la ou para argumentar em sentido contrário.

Koch (2004) retoma, ainda, o conceito de valor das operações transtextuais em Grésillon e Maingueneau (1984), que ajuda a distinguir tais operações em termos dos seus efeitos éticos e estéticos. No caso do valor de captação, temos paráfrases relativamente próximas do texto fonte, enquanto, no caso do valor de subversão, destacam-se enunciados paródicos e/ou irônicos, formulações de tipo concessivo e apropriações. Em ambos os casos, espera-se que os leitores/ouvintes consigam reconhecer o intertexto por meio da ativação de sua memória discursiva, uma vez que, sem isso, a significação estará prejudicada. Mas há casos extremos de captação em que o produtor espera que o interlocutor não tenha acesso à memória coletiva relativa ao intertexto, tentando, por vezes, dificultar a ativação dessa memória ao "camuflar" o intertexto por meio de operações linguísticas "de pequena monta 
(apagamentos, substituições de termos, alterações de ordem sintática, transposiçōes etc.)" (KOCH, 2004, p. 147). Neste caso, temos o plágio.?

Como Koch (2004), Marcuschi (2000) também ressalta processos de retextualização como operações usuais na trajetória de produção de textos em determinadas práticas - por exemplo, em processos de editoraçāo ou de confecção de processos judiciais. A despeito de essas operaçōes linguísticas poderem ser, entre outras, as mesmas usadas no plágio, talvez variando apenas em termos de abrangência e esforço envolvido, não está em jogo, no caso da retextualização não plagiária, a autoria ou propriedade intelectual do texto, de modo que o valor de captação não necessita ser camuflado. Além disso, as operaçōes de substituição, seleção, acréscimo, reorganização e condensação, embora não sejam rastreáveis diretamente a partir do texto final, não necessitam ser omitidas, podendo até mesmo ser objeto de estudo e/ou apreciação, como no caso da crítica genética, ou das pedagogias de escrita colaborativa e/ou processual.

Acreditamos que tanto o conceito de valor como a noção de retextualização são úteis para situar remix e mashup no quadro geral das manifestações empíricas da transtextualidade. Para isso, devemos considerar que são, basicamente, casos extremos de captação em que a recuperação dos intertextos na memória discursiva do leitor não é obstante, mas sim incentivada, e casos de retextualização de textos que já estavam na memória coletiva, e, portanto, continuações - autorizadas ou não, desejáveis ou não - da trajetória que permitiu o estabelecimento público da autoria e/ou propriedade intelectual. Ao mesmo tempo em que não constituem plágio, reivindicam para si algo como uma "autoria derivada", marcada, justamente, pela capacidade de retomar a trajetória de retextualização revitalizando o texto fonte na memória coletiva.

\subsection{A perspectiva da Teoria Literária}

Genette (2006 [1982]) define transtextualidade (ou transcendência textual) como tudo que coloca um texto em relação - manifesta ou secreta com outros textos, e especifica cinco tipos de relações transtextuais em ordem crescente de abstração, implicitude e globalidade: intertextualidade, paratextualidade, metatextualidade, arquitextualidade e hipertextualidade.

\footnotetext{
${ }^{7}$ Como exemplo prático para a compreensão do plágio como caso extremo de captação, podemos citar o plágio escolar. Quando um aluno desenvolve essa estratégia discursiva, o seu desejo final é obter um texto que ele julga ser melhor do que aquele que ele poderia produzir sozinho, tendo, digamos, somente a sua memória discursiva a serviço da elaboração de sua atividade.
} 
A paratextualidade caracteriza-se pela relação menos explícita e mais distante entre o que seria o corpo do texto e os "sinais acessórios" que ocupam seu entorno "variável" (epígrafes, títulos, subtítulos, notas à margem do texto, entre outros). A metatextualidade consiste numa relação de "comentário", que une um texto a outro que fala dele sem convocá-lo e/ou nomeá-lo explicitamente, ao passo que a arquitextualidade seria a forma mais implícita e abstrata de transtextualidade, muitas vezes limitada ao puro pertencimento taxonômico. Finalmente, a hipertextualidade seria toda a relação que une um texto B (hipertexto) a um texto A (hipotexto), no qual se enxerta de uma maneira outra que não a do comentário (em contraste com a metatextualidade). Entendemos que, embora todas essas relações transtextuais sejam importantes, não são necessariamente úteis a nosso propósito e, por isso, como fizemos na subseção anterior, vamos nos ater à intertextualidade. $^{8}$

De forma congruente a Koch (2004), Genette (2006 [1982]) vê a intertextualidade como a relação de copresença efetiva de um texto em outro e, novamente como Koch (2004), revelada de modo explícito ou implícito. Acrescenta, porém, dois traços distintivos adicionais para as diferentes manifestações da intertextualidade: a literalidade e a adesão ao cânone. Assim, o plágio, por exemplo, seria um caso de intertextualidade menos explícita, mais literal e menos canônica do que a citação com aspas, enquanto a alusão seria uma forma canônica menos explícita do que a citação e menos literal do que o plágio (GENETTE, 2006 [1982]). Quanto a remix e mashup, diremos que, além de explícitos, são altamente literais, porém usualmente muito pouco canônicos, exceto, talvez, no caso dos remixes estendidos.

Ainda no quadro da Teoria Literária, é útil recorrer à reflexão de Affonso Romano de Sant'Anna (2003 [1985]) acerca de três formas específicas de manifestação da transtextualidade e/ou intertextualidade: a paródia, a paráfrase e a estilização. A paráfrase estaria, para Sant'Anna, mais próxima de um tipo de continuidade com o texto fonte e de descontinuidade com a paródia, enquanto a estilização ficaria a meio caminho. Dito de outro modo, em relação ao texto fonte, "a paródia deforma, a paráfrase conforma e a estilização reforma” (SANT’ANNA, 2003 [1985], p. 41).

${ }^{8}$ É importante ressaltar que, para Genette (2006 [1982]), não se pode considerar essas relações transtextuais como classes estanques, sem comunicação ou entrelaçamentos recíprocos, e que, como mencionamos acima a propósito de mashups não regressivos, tais relações necessitam ser invocadas por um leitor que não se comporte como mero receptor, mas como um gerador e buscador de relações transtextuais, ou, em outras palavras, um "transleitor". 
Pensando no quadro geral proposto na subseção anterior, pode-se dizer que os remixes estendido e seletivo parafraseiam e estilizam ao mesmo tempo, enquanto o remix reflexivo deforma o texto fonte. Nisso, o remix reflexivo se aproxima da paródia, embora não compartilhe com a paródia, necessariamente, a predominância do valor de subversão (MAINGUENEAU, 1997). Já os mashups de conteúdo e de dados se distinguem tanto da paráfrase quanto da estilização e da paródia por terem, necessariamente, mais de um texto fonte em sua constituição intertextual. Note-se, contudo, que os mashups regressivos se aproximam tanto da paráfrase, pelo valor de empréstimo, quanto da paródia, pelo valor de subversão, o que, obviamente, só é possível porque mashups são "montagens" em que partes de certas fontes são copiadas fielmente, mas combinadas "infielmente" com outras partes de outras fontes.

\subsection{Paródia: um caso especial}

É comum encontrarmos referências aos casos que aqui consideramos remixes e mashups como sendo "paródias de Internet" e, por isso mesmo, acreditamos que vale a pena estender a comparação com a paródia para além do proposto por Sant'Anna (2003 [1985]).

Recorremos, para tanto, a Bakhtin (2002 [1975], p. 389), que define a paródia como um "híbrido premeditado", para ressaltar a impossibilidade de separarmos as duas vozes e/ou consciências que a paródia, enquanto enunciado, carrega simultaneamente. Bakhtin faz notar, ainda, que a diferença entre a paródia e o texto fonte pode estar evidenciada pelo gênero, isto é, que normalmente os gêneros paródicos são diferentes dos gêneros parodiados, já que estes não raro são decadentes, desgastados pelo uso e, por isso mesmo, alvo das deformações, visão que se aproxima da de Sant'Anna (2003 [1985]).

Ora, embora mashups e remixes também possam, em certos casos, ser identificados como tal por subverterem, substituírem ou, no mínimo, perturbarem, de alguma forma, o gênero dos textos fonte, e embora também abriguem múltiplas vozes, vale ressaltar que, nesses "produtos", isso tudo se produz por meio de montagem, ou seja, pelo acionamento de encaixes e ganchos que permanecem visíveis, e não como define Bakhtin (2002 [1975]) para a paródia, por meio de um novo enunciado e/ou gênero apresentado "sem costura".

9 BUZATO (2007) explora esse mesmo conceito para estudar o hibridismo constitutivo de uma página da Web, mostrando como as vozes programador/designer e do autor/leitor estabelecem um enunciado ambíguo, porém não antagônico. 
Vale notar, contudo, que remix, mashup e paródia podem ser vistos como mais próximos entre si do que é possível na visão inspirada pelas definiçōes de Bakhtin e Sant'Anna quando se parte para uma perspectiva alternativa à de que a paródia necessariamente deforma o texto fonte. Este é o caso de Linda Hutcheon (1989), para quem a paródia (quer seja na literatura, no cinema, na música ou na arquitetura) é basicamente "repetição, mas repetição que inclui diferença; é imitação com distância crítica, cuja ironia pode beneficiar e prejudicar ao mesmo tempo", implicando um ethos pragmático que vai "do ridículo desdenhoso à homenagem reverencial" (HUTCHEON, 1989, p. 54). Entendemos que, ao falar em "repetição que inclui diferença” e "homenagem reverencial", Hutcheon aponta inequivocamente para alguns tipos de remix aqui mencionados, e ao se referir a uma "distância crítica cuja ironia pode beneficiar e prejudicar ao mesmo tempo", fala em alguma medida do que aqui chamamos de mashups de conteúdo.

Ainda acerca da paródia, vale resgatar que esta compartilha com o pastiche (outra tradicional manifestação da transtextualidade) o procedimento da imitação, neste caso não de um texto fonte em particular, mas do estilo idiossincrático de um autor, movimento ou escola nas artes visuais, na literatura, cinema, arquitetura ou música. Tal imitação, como no caso da paródia, nem sempre tem como intenção a sátira, ${ }^{10}$ embora isso seja possível, mas envolve, necessariamente, a apropriação de uma miscelânea de obras ou partes de obras, e não uma única fonte em sua integralidade. $\mathrm{O}$ pastiche seria, portanto, uma forma de manifestação da transtextualidade a meio caminho entre a paródia e o mashup.

Por fim, há que se distinguir paródia, remix e mashup de détournement, ${ }^{11}$ palavra francesa que significa 'desvio', 'reencaminhamento', ou 'malversação'. Tal forma de manifestação da transtextualidade "consiste em produzir um enunciado que possui as marcas linguísticas de uma enunciação proverbial, mas que não pertence ao estoque dos provérbios reconhecidos" (GRÉSILLON; MAINGUENEAU, 1984, p. 114). Assim como a paródia, o détournement prioriza a expressão lúdica (não necessariamente irônica) e antagônica (não necessariamente destrutiva) em sua adaptação do texto fonte, mas, diferentemente

\footnotetext{
${ }^{10}$ Para Genette (2006 [1982]), enquanto a paródia se dá por transformação, mínima, de um texto, o pastiche constitui-se por imitação de um estilo sem qualquer função crítica ou satírica.

${ }^{11}$ A terminologia aplicada é retirada de Koch (2004).
} 
da paródia, e de forma semelhante ao que fazem o mashup de conteúdo e o remix reflexivo, em parte repete e em parte contradiz sua forma. ${ }^{12}$

Encerramos a presente seção sintetizando nossos achados nesta investigação de um possível lugar para remix e mashup na ecologia das manifestaçóes empíricas da transtextualidade, como mostra o QUADRO 2.

\section{QUADRO 2}

Manifestaçōes empíricas da transtextualidade

\begin{tabular}{|c|c|c|c|c|c|}
\hline $\begin{array}{l}\text { Produção } \\
\text { transtextual }\end{array}$ & $\begin{array}{c}\text { Objetivo } \\
\text { do produtor }\end{array}$ & $\begin{array}{c}\text { Efeito } \\
\text { almejado }\end{array}$ & $\begin{array}{c}\text { Operações } \\
\text { de forma }\end{array}$ & $\begin{array}{c}\text { Operações } \\
\text { de conteúdo }\end{array}$ & $\begin{array}{c}\text { Traço } \\
\text { identificador }\end{array}$ \\
\hline $\begin{array}{l}\text { Plágio } \\
\text { (forgérie) }\end{array}$ & $\begin{array}{c}\text { Passar-se por "autor" / } \\
\text { Fazer seu texto } \\
\text { passar-se por fonte }\end{array}$ & $\begin{array}{c}\text { Identidade } \\
\text { total (com uma } \\
\text { ou mais fontes) }\end{array}$ & $\begin{array}{l}\text { Repete com } \\
\text { ajustes mínimos }\end{array}$ & $\begin{array}{l}\text { Repete com } \\
\text { ajustes mínimos }\end{array}$ & $\begin{array}{l}\text { Dificulta proposital- } \\
\text { mente a recuperação } \\
\text { da fonte pelo leitor }\end{array}$ \\
\hline Paródia & $\begin{array}{c}\text { Ridicularizar, criticar, } \\
\text { ou destruir a fonte e/ou } \\
\text { seu autor e/ou seu estilo }\end{array}$ & $\begin{array}{l}\text { Dissonância } \\
\text { (uma fonte) }\end{array}$ & Repete & Permuta & $\begin{array}{l}\text { Híbrido proposital que } \\
\text { produz um contraestilo }\end{array}$ \\
\hline Paráfrase & $\begin{array}{l}\text { Conformar seu texto } \\
\text { com o teor da fonte }\end{array}$ & $\begin{array}{l}\text { Consonância } \\
\text { (uma fonte) }\end{array}$ & Permuta & Repete & $\begin{array}{c}\text { Remedia a (falta de) } \\
\text { memória discursiva } \\
\text { do leitor }\end{array}$ \\
\hline $\begin{array}{l}\text { Remix seletivo } \\
\text { ou estendido }\end{array}$ & $\begin{array}{l}\text { Celebrar a fonte e/ou } \\
\text { seu autor e/ou } \\
\text { seu estilo }\end{array}$ & $\begin{array}{c}\text { Eco } \\
\text { (uma fonte) }\end{array}$ & $\begin{array}{l}\text { Repete com } \\
\text { ajustes mínimos }\end{array}$ & $\begin{array}{c}\text { Repete, acrescenta } \\
\text { e/ou subtrai }\end{array}$ & Estiliza preservando \\
\hline $\begin{array}{l}\text { Remix } \\
\text { reflexivo }\end{array}$ & Reinventar a fonte & $\begin{array}{l}\text { Reverberação } \\
\text { (uma fonte) }\end{array}$ & $\begin{array}{c}\text { Repete com } \\
\text { diferença máxima }\end{array}$ & Reelabora & Estiliza transformando \\
\hline $\begin{array}{l}\text { Mashup } \\
\text { regressivo }\end{array}$ & $\begin{array}{c}\text { Reaproveitar as } \\
\text { fontes para outros/ } \\
\text { novos fins }\end{array}$ & $\begin{array}{l}\text { Contracanto } \\
\text { (mais de } \\
\text { uma fonte) }\end{array}$ & $\begin{array}{l}\text { Repete } \\
\text { recombinando }\end{array}$ & Reatualiza & $\begin{array}{l}\text { Híbrido proposital em } \\
\text { que a mensagem } \\
\text { referencial compete } \\
\text { com uma mensagem } \\
\text { metassemiótica }\end{array}$ \\
\hline $\begin{array}{l}\text { Mashup de } \\
\text { serviços (remix } \\
\text { regenerativo) }\end{array}$ & $\begin{array}{c}\text { Somar fontes para } \\
\text { multiplicar propósitos } \\
\text { práticos }\end{array}$ & $\begin{array}{l}\text { Estereofonia } \\
\text { (mais de } \\
\text { uma fonte) }\end{array}$ & $\begin{array}{l}\text { Agrega e/ou } \\
\text { integra }\end{array}$ & $\begin{array}{l}\text { Agrega e/ou } \\
\text { integra }\end{array}$ & $\begin{array}{c}\text { Depende "vitalmente" } \\
\text { da manutenção } \\
\text { da(s) fonte(s) }\end{array}$ \\
\hline Pastiche & $\begin{array}{l}\text { Emprestar idiossin- } \\
\text { crasias da(s) fonte(s) } \\
\text { um propósito estético }\end{array}$ & $\begin{array}{c}\text { Reflexo } \\
\text { (uma ou } \\
\text { mais fontes) }\end{array}$ & $\begin{array}{c}\text { Repete } \\
\text { seletivamente }\end{array}$ & $\begin{array}{l}\text { Reambienta e } \\
\text { recontextualiza }\end{array}$ & $\begin{array}{c}\text { Homenageia a fonte ao } \\
\text { mesmo tempo em que } \\
\text { a enfraquece }\end{array}$ \\
\hline$\overline{\text { Détournement }}$ & $\begin{array}{l}\text { Desviar o curso } \\
\text { do texto fonte }\end{array}$ & $\begin{array}{l}\text { Refração (uma } \\
\text { ou mais fontes) }\end{array}$ & $\begin{array}{c}\text { Repete } \\
\text { seletivamente }\end{array}$ & Contradiz & $\begin{array}{l}\text { Proverbializa o banal } \\
\text { e banaliza o proverbial }\end{array}$ \\
\hline
\end{tabular}

Relações entre texto fonte e texto derivado nas manifestações transtextuais abordadas neste trabalho.

Fonte: Elaboração própria.

${ }^{12}$ Citamos como exemplos os seguintes slogans publicitários listados pela pesquisadora Denise Durante no blog Linguagem, argumentação e discurso: "Kaiser Gold: Nem tudo o que reluz é ouro. Às vezes, é cerveja"; "Chrysler: Por trás de todo homem tem sempre um banco de couro que é uma delícia!"; "Sony Ericsso: Z300i. As aparências não enganam”. Disponível em: <http://denisedurante.blogspot. com.br/ 2011/09/exemplos-de-detournement-na-publicidade.html>. Acesso em: 2 jul. 2013. 
É importante destacar, como no caso da taxonomia proposta, que essas distinções são analiticamente úteis, porém necessariamente porosas e podem inclusive aparecer combinadas em uma mesma produção textual, como, por exemplo, quando uma paródia é retomada por um plagiador, ou um remix é aproveitado como fonte para um mashup.

\section{Considerações finais}

Vale retomar, em conclusão, que remix e mashup são formas culturais, métodos e processos de atividade semiótico-discursiva que já existiam e já haviam sido desenvolvidos e pesquisados no âmbito das mídias e linguagens analógicas (música, cinema, literatura, artes visuais, arquitetura, gastronomia e assim por diante), mas que, no âmbito da cultura digital (ou da cibercultura remix, como quer Lemos [2005], ou das culturas mashup, como quer Sonvilla-Weiss [2010]) ganham uma nova relevância quantitativa e qualitativa. Mas pode-se ir além, afirmando que teorizar remix e mashup, mesmo no âmbito do digital, é simplesmente continuar uma longa tradição de investigação sobre a força do hibridismo nas dinâmicas culturais em geral (FRIEDMAN, 2002). O que procuramos destacar aqui, em especial, é que os remixes e mashups digitais remetem a um tipo muito especial de hibridização, o qual não apenas tematiza o que seria a ética pós-industrial de que falam Lankshear e Knobel (2007), mas coloca em diálogo com a mentalidade tecnocientífica, vigente no empreendimento purificador que caracteriza a forma de agir e pensar dos engenheiros e cientistas criadores de novas tecnologias (LATOUR, 1994), a mentalidade "primeira" mais do que "primitiva" do bricoleur a que se referia Lévi-Strauss (1989).

Dito de outra forma, remixes e mashups digitais são a expressão concreta de uma relação estabelecida entre um punhado de racionalizações sistematicamente inscritas por engenheiros em mecanismos cibernéticos e o desejo atávico de toda uma geração de meaning makers de ressignificar o já significado (ou redesign os available designs, como queria o The New London Group [1996]), pela potência da mesma bricolagem que observamos na grande mistura de bancos de dados e narrativas, taxonomias e folksonomias, protocolos e gambiarras que constituem a Internet, e os letramentos a ela associados (BUZATO, 2009).

Não por acaso, esse encontro improvável entre meios e desejos tem gerado embates políticos importantes na atualidade, sobretudo no que tange aos conceitos de copyright e propriedade intelectual. 
Uma das maneiras empregadas pelas corporações para impor uma política de proteção ao copyright por meio da própria tecnologia é justamente a existência de formatos de arquivo distintos para os objetos (vídeos, animaçôes, música, jogos etc.) enquanto projetos (arquivos que permitem a desmontagem do objeto em camadas) e enquanto produtos (arquivos que podem ser executados ou exibidos, mas são blindados para funcionar como sendo uma única camada). Por esse ângulo, novamente emerge a identidade contingente e relacional disso que chamamos de remix e o mashup: legitimados por esses produtores oficiais como métodos/técnicas poderosos de autoria (para eles); demonizados como métodos/técnicas de burla do copyright a serem combatidas (para os outros).

Mais do que fonte de disputas legais em escala industrial (FERGUSON, 2010; 2011; 2012), a complexidade política das relações entre estética e ética nessas produções está, ou deveria estar, fortemente implicada nas suas possibilidades educacionais, haja vista os muitos "mal-entendidos culturais" e disputas dos sentidos de autoria, conhecimento e trabalho intelectual vigentes no contato entre os jovens brasileiros e a instituição escolar hoje (BUZATO, 2010b).

Lankshear e Knobel (2008), por exemplo, ressaltam a grande relevância das culturas remix e mashup para a educação, por envolverem o trabalho com ferramentas tecnológicas que, em sua maioria, são adquiridas e dominadas de maneira mais pronta e efetiva em contextos de práticas situadas de produção para audiências autênticas, sob condições em que apoio, experiência e feedback estão disponíveis a qualquer momento e em qualquer lugar - práticas em que isso é construtivo em vez de punitivo, em que se reconhece que os avanços se dão em "níveis", como num jogo, e não como tudo ou nada, tal qual em provas de aprovação ou reprovação.

Lamb (2007) aponta para essas mesmas questōes, ressaltando que características da cultura remix/mashup potencialmente úteis ao ensino - como o engajamento coletivo em comunidades de conhecimento nas quais os usuários são também produtores dos artefatos semiótico-discursivos que ali circulam - só poderão ser efetivamente aproveitadas se acompanhadas de políticas de licenciamento sérias e legalmente eficazes, como é o caso da Creative Commons (LESSIG, 2004). Podemos pensar aqui, por exemplo, na produsagem (BRUNS, 2008) de objetos de aprendizagem (LEFFA, 2006) que misturem conteúdos midiáticos com os quais os alunos se identifiquem fortemente (LEMKE, 2009) via remix e mashup enquanto processos e 
métodos, o que, sem o devido licenciamento, constituiria, hoje, strictu senso, um ato infracional criminal por parte da escola!

É nossa convicção que, entre os benefícios obtidos em troca dos reducionismos implicados no tipo de trabalho que aqui propusemos, estão ganhos de inteligibilidade sobre o fenômeno que permitirão algum tipo de avanço nesses impasses institucionais e interculturais. Acreditamos, sobretudo, que é necessário recusar a banalização dos conceitos de remix e mashup que parece acompanhar a difusão do acesso às suas ferramentas e técnicas de produção e consumo, sob pena de, não o fazendo, perdermos um instrumento importante para a legitimação educacional da reflexividade, agentividade e relevância política agregadas a essas práticas.

Dito de outra forma, legitimar remix e mashup como objetos de pesquisa e de ensino é possivelmente indispensável para que a escola possa, um dia, transformar sujeitos transleitores e transletrados em cidadãos capazes de protagonizar mudanças sociais a partir do momento em que tiverem consciência sobre a força política dos hibridismos propositais, quer sejam entre gêneros, mídias, modalidades, linguagens e textos, ou entre engenharia e bricolagem, global e local, humano e não humano (BUZATO, 2010a; 2012).

Como dissemos antes, esta é apenas uma proposta inicial, um começo de percurso: esperamos ter deixado, contudo, ganchos e encaixes suficientemente claros e úteis aos que nos queiram remixar reflexivamente.

\section{Referências}

BAKHTIN, M. Questôes de literatura e de estética: a teoria do romance. 5. ed. São Paulo: Hucitec/Annablume, 2002.

BARROS, N. N. Apropriação da curadoria na web por uma empresa de mídia tradicional: a cultura da convergência entre a narrativa e o banco de dados. Dissertação (Mestrado em Linguística Aplicada) - Instituto de Estudos da Linguagem, Universidade Estadual de Campinas, Campinas, em preparação.

BENJAMIN, W. A obra de arte na época de sua reprodutibilidade técnica. In: ADORNO, T. et al. Teoria da cultura de massa. Tradução de Carlos Nelson Coutinho. São Paulo: Paz e Terra, 2000. p. 221-254.

BOLTER, J. D.; GRUSIN, R. A. Remediation: Understanding New Media. Cambridge (MA): MIT, 2000.

BRUNS, A. Introduction. In: Blogs, Wikipedia, Second Life, and Beyond: From Production to Produsage. Nova York: Peter Lang, 2008. p. 1-7. 
BRUNS, A. Produsage, Generation C, and Their Effects on the Democratic Process. In: MEDIA IN TRANSITION, 5., 27-29 Apr. 2007, Boston. Proceedings... Boston: MIT, 2007. Disponível em: <http://eprints.qut.edu.au/ 7521/>. Acesso em: 2 jul. 2013.

BUZATO, M. E. K. Can Reading a Robot Derobotize a Reader? Trabalhos em Linguística Aplicada, Campinas, v. 49, n. 2, p. 359-372, 2010a.

BUZATO, M. E. K. Cultura digital e apropriação ascendente: apontamentos para uma educação 2.0. Educação em Revista, Belo Horizonte, v. 26, n. 3, p. 283303, 2010b.

BUZATO, M. E. K. Dinâmicas de apropriação e a constituição de transletramentos no contexto de um telecentro comunitário. In: CONGRESSO INTERNACIONAL DA ABRALIN, 6., 2009, João Pessoa. Anais... João Pessoa: ABRALIN, 2009. p. $2749-2758$.

BUZATO, M. E. K. Letramentos multimodais críticos: contornos e possibilidades. Revista CROP, São Paulo, v. 12, p. 108-144, 2007.

BUZATO, M. E. K. Práticas de letramento na ótica da Teoria Ator-Rede: casos comparados. Calidoscópio, São Leopoldo, v. 10, n. 1, p. 65-82, 2012.

CHARTIER, R. Os desafios da escrita. São Paulo: Editora UNESP, 2002.

CHATTI, M. A.; JARKE, M.; SPECHT, M. Model-Driven Mashup Personal Learning Environments. International Journal of Technology Enhanced Learning, v. 3, n. 1, p. 21-44, 2011.

CONKLIN, J. Hypertext: An Introduction and Survey. Computer, v. 20, n. 9, p. 17-41, 1987.

COSER, D. S. Galanet versus Busuu: um estudo comparativo de duas comunidades de aprendizagem colaborativa de línguas online. Dissertação (Mestrado em Linguística Aplicada) - Instituto de Estudos da Linguagem, Universidade Estadual de Campinas, Campinas, em preparação.

DEBORD, G. Society of the Spectacle. New York: Zone, 2004.

DEUZE, M.; BRUNS, A.; NEUBERGER, C. Preparing for an Age of Participatory News. Journalism Practice, v. 1, n. 3, p. 322-338, 2007.

FRIEDMAN, S. S. 'Border Talk', hybridity, and performativity: Cultural Theory and Identity in the Spaces between Difference. Revista Critica de Ciências Sociais, Coimbra, n. 61, p. 1-17, 2002. Disponível em: <http://eurozine.com/pdf/ 2002-06-07-friedman-en.pdf>. Acesso em: 20 jun. 2013.

GENETTE, G. Palimpsestos: a literatura de segunda mão. Tradução de Luciene Guimarães e Maria Antônia Ramos Coutinho. Belo Horizonte: Faculdade de Letras da UFMG, 2006. (Livros Viva Voz). 
GRÉSILLON, A.; MAINGUENEAU, D. Polyphonie, proverbe et détournement, ou un proverbe peut en cacher un autre. Langages, v. 19, n. 73, p. 112-125, 1984. HALL, S. Da diáspora: identidades e mediações culturais. Tradução de Adelaide La Guardia Resende et al. Belo Horizonte: Editora UFMG; Brasília: Representação da UNESCO no Brasil, 2003.

HUTCHEON, L. The Politics of Postmodernism. London; New York: Routledge, 1989.

JENKINS, H. Cultura da convergência. 2. ed. São Paulo: Aleph, 2009.

KOCH, I. Introdução à lingüistica textual. São Paulo: Martins Fontes, 2004.

LAMB, B. Dr. Mashup or, Why Educators Should Learn to Stop Worrying and Love the Remix. Educause Review, v. 42, p. 12-25, 2007.

LANDOW, G. P. Hypertext: The Convergence of Contemporary Critical Theory and Technology. Baltimore: Johns Hopkins, 1992.

LANKSHEAR, C.; KNOBEL, M. Remix: The Art and Craft of Endless Hybridization. Journal of Adolescent \& Adult Literacy, v. 54, n. 1, p. 22-33, 2008. LANKSHEAR, C.; KNOBEL, M. Sampling "The New” in New Literacies. In: . (Ed.). A New Literacies Sampler. Nova York: Peter Lang, 2007. p. 1-24.

LATOUR, B. Jamais fomos modernos: ensaio de antropologia simétrica. Rio de Janeiro: Editora 34, 1994.

LEFFA, V. J. Nem tudo que balança cai: objetos de aprendizagem no ensino de línguas. Polifonia, Cuiabá, v. 12, n. 2, p. 15-45, 2006.

LEMKE, J. L. Metamedia Literacy: Transforming Meanings and Media. In: REINKING, D. et al. (Ed.). Literacy for the $21^{\text {st }}$ Century: Technological Transformation in a Post-Typographic World. Hillsdale: Erlbaum, 1998. p. 238-301. Disponível em: <http://academic.brooklyn.cuny.edu/education/ jlemke/reinking.htm>. Acesso em: 30 jun. 2013.

LEMKE, J. L. Multimodality, Identity, and Time. In: JEWITT, C. (Ed.). The Routledge Handbook of Multimodal Analysis. London: Routledge, 2009. p. 140-150. LEMKE, J. L. Travels in Hypermodality. Visual Communication, v. 1, n. 3, p. 299-325, 2002.

LEMOS, A. Ciber-cultura-remix. Apresentação na mesa "Redes: criação e reconfiguração”, do Seminário Sentidos e Processos, São Paulo, Itaú Cultural, ago. 2005. Disponível em: <http://www.hrenatoh.net/curso/textos/andrelemos_remix.pdfs. Acesso em: 7 maio 2013.

LESSIG, L. Free Culture: The Nature and Future of Creativity. Nova York: Penguin, 2004. 
LÉVI-STRAUSS, C. Pensamento selvagem. Tradução de Tânia Pellegrini. Campinas: Papirus, 1989.

MAINGUENEAU, D. Novas tendências em análise do discurso. Campinas: Pontes/Editora da Unicamp, 1997.

MANOVICH, L. New Media from Borges to HTML. In: WARDRIP-FRUIN, N.; MONTFORT, N. (Ed.). The New Media Reader. Cambridge (MA): MIT Press, 2003. p. 13-25.

MANOVICH, L. The Language of New Media. London: MIT Press, 2001. p. 18-61.

MARCUSCHI, L. A. Da fala para a escrita: atividades de retextualização. 2. ed. São Paulo: Cortez, 2000.

NAVAS, E. Regressive and Reflexive Mashups in Sampling Culture. In: SONVILLA-WEISS, S. (Ed.). Mashup Cultures. Wien; New York: Springer, 2010. p. 157-177.

NELSON, T. H. Opening Hypertext: A Memoir. In: TUMAN, M. C. (Ed.). Literacy On-line: The Promise (and Peril) of Reading and Writing with Computers. Pittsburgh: University of Pittsburgh Press, 1992. p. 43-57.

NIELSEN, J. Participation Inequality: Encouraging More Users to Contribute. 2006. Disponível em: <http://www.nngroup.com/articles/participationinequality>. Acesso em: 1 jun. 2013.

SACHS, R. S. Travessias hipermodais em letramentos dos fâs de Glee: da produsagem à reflexão metadiscursiva. 2012. $112 \mathrm{f}$. Trabalho de conclusão de curso (Graduação em Letras) - Instituto de Estudos da Linguagem, Universidade Estadual de Campinas, Campinas, 2012. Disponível em: <http://www.bibliotecadigital. unicamp.br/document/?code=54570\&opt=1>. Acesso em: 30 jun. 2013.

SANT'ANNA, A. R. Paródia, paráfrase \&r cia. São Paulo: Ática, 2003. Disponível em: <http:/www.scribd.com/doc/6180365/Affonso-Romano-de-SantAnnaParodia-Parafrase-e-CIA-PDF-Rev>. Acesso em: 7 maio 2013.

SILVA, D. P. Práticas de letramentos em jogo de construção colaborativa: MUD Valinor. 2012. 205 f. Dissertação (Mestrado em Linguística Aplicada) - Instituto de Estudos da Linguagem, Universidade Estadual de Campinas, Campinas, 2012. SONVILLA-WEISS, S. Introduction: Mashups, Remix, Practices and the Recombination of Existing Digital Content. In: SONVILLA-WEISS, S. (Ed.). Mashup Cultures. Wien; New York: Springer, 2010. p. 8-23.

THE NEW LONDON GROUP. A Pedagogy of Multiliteracies: Designing Social Futures. Harvard Educational Review, v. 66, n. 1, p. 60-93, 1996. 
THOMAS, S. et al. Transliteracy: Crossing Divides. First Monday, v. 12, n. 12, 2007. Não paginado.

YEE, R. Pro Web 2.0 Mashups Remixing Data and Web Services. Berkeley; New York: Apress, 2008. Disponível em: <http://www.books24x7.com/marc.asp?bookid= 25487>. Acesso em: 7 maio 2013.

\section{Documento iconográfico em formato eletrônico}

Google Maps - Flickr - GoogleMaps Mashup. Captura de imagem por satélite. Disponível em: <http://goo.gl/maps/RlUH4>. Acesso em: 30 jun. 2013.

\section{Vídeos}

Adele - Set Fire to the Rain (Dj Tyler Davey Extended Remix). Produção: Tyler Davey. Distribuição: independente. 2012. Vídeo - documentário (7:31 min.). Disponível em: <http://www.youtube.com/watch?v=j1UTQxc2I4c>. Acesso em: 1 jun. 2013.

Everything Is a Remix, Part I: The Song Remains the Same. Direção e roteiro: Kirby Ferguson. Distribuição: independente. 2010. Vídeo - documentário (7:18 min.). Disponível em: <http://everythingisaremix.info/watch-the-series>. Acesso em: 1 jun. 2013.

Everything Is a Remix, Part II: Remix INC. Direção e roteiro: Kirby Ferguson. Distribuição: independente. 2011. Vídeo - documentário (9:48 min.). Disponível em: <http://everythingisaremix.info/watch-the-series/>. Acesso em: 1 jun. 2013.

Everything Is a Remix, Part III: The Elements of Creativity. Direção e roteiro: Kirby Ferguson. Distribuição: independente. 2011. Vídeo - documentário (11:17 min.). Disponível em: <http://everythingisaremix.info/watch-theseries>. Acesso em: 1 jun. 2013.

Everything Is a Remix, Part IV: System Failure. Direção e roteiro: Kirby Ferguson. Distribuição: independente. 2012. Vídeo - documentário (15:26 min.). Disponível em: <http://everythingisaremix.info/watch-the-series > . Acesso em: 1 jun. 2013.

Kanye West - Gold Digger ft. Jamie Foxx (Music Video by Kanye West Performing Gold Digger). Produção: John Brion e Kanye West. Distribuição: Roc-A-Fella Records, LLC. 2005. Vídeo (3:42 min.). Disponível em: <http:// www.youtube.com/watch?v=6vwNcNOTVzY>. Acesso em: 1 jun. 2013. 
O bonde das maravilhas (versão Teletubbie). Vídeo (2:23 min.). Disponível em: <http://www.youtube.com/watch?v=tZt8zf1Ms2k>. Acesso em: 1 jun. 2013. Ray Charles - I Got a Woman. Áudio (2:56 min.). Disponível em: <http:// www.youtube.com/watch?v=Mrd14PxaUco >. Acesso em: 1 jun. 2013.

System of a Dilma. Dj Faroff e Xandelai. Distribuição: independente. 2011. Vídeo - mashup (1:38 min.). Disponível em: <http://www.youtube.com/ watch?v=OS3Lh6vc1 ts>. Acesso em: 1 jun. 2013.

The Southern Tones “It Must Be Jesus” 1954 Duke 205 Gospel Series. Áudio (2:57 min.). Disponível em: <http://www.youtube.com/watch?v=AvCbVLZW4EY>. Acesso em: 1 jun. 2013.

Titanic in 5 seconds. 2007. Vídeo - remix do filme Titanic (12 seg.). Disponível em: <http://www.youtube.com/watch?v=OuSdU8tbcHY>. Acesso em: 1 jun. 2013. 